\title{
O processo criativo do poema "The Burglar of Babylon" a partir de uma abordagem sociocrítica
}

\section{Introdução}

NA CONTEMPORANEIDADE, NOTA-SE UM ALTO ÍNDICE DE DESENVOLVIMENTO DE PRODUÇÕES CIENTÍFICAS E ARTÍSTICAS NAS CIÊNCIAS HUMANAS E NOS ESTUDOS CULTURAIS DIRECIONADOS À TEMÁTICA SÓCIO-HISTÓRICA, POLÍTICA E/OU a retomada de estudos e conceitos já pré-estabelecidos pela epistemologia do século anterior. Nesse sentido, a crítica genética, após quase quatro décadas de sua chegada ao Brasil, tem se destacado no cenário acadêmico por seu caráter dinâmico, heterogêneo e, por vezes, transgressor. A transdisciplinaridade identificada em cada processo criativo acabou tornando-se um convite para que os estudiosos começassem a pensar esse campo de pesquisa como transartístico e também transemiótico ${ }^{3}$.

Com o desenvolvimento da disciplina, o prototexto passa a não se restringir apenas ao manuscrito literário como única materialidade passível de estudo, mas a acolher materiais de análise diversificados, a exemplo dos rascunhos resultantes da atividade tradutória, dos diversos registros da criação de materiais audiovisuais, dos planos e esboços de pinturas, dentre outras formas de registro. De fato, há uma infinidade de materiais do campo artístico e científico que se caracterizam como possíveis objetos de estudo da crítica genética. Além disso, com as novas tecnologias, o estudo do processo criativo se torna tarefa árdua, pois diversificam-se as formas de materialização da obra e, por conseguinte, de acesso a seus registros de criação.

No que se refere ao estudo de objetos literários, destacamos a complexidade que pode ser encontrada nos manuscritos de um texto narrativo ou poético, os quais podem estabelecer relação com o mundo real de tal forma que o escritor acaba produzindo uma obra que contribui para o levantamento de dados históricos, especialmente quando não abordados pela história tradicional. Diante de um material de tal natureza, como é o caso do poema "The Burglar of Babylon", optamos por realizar um estudo sociocrítico. Tal abordagem se torna possível porque a literatura, por meio do imaginário de um escritor, transfigura aspectos sociais, econômicos e políticos provindos do mundo real, o que requer do pesquisador habilidade para a realização de um estudo transdisciplinar com vistas a remontar a história de uma individualidade que, muitas vezes, é pouco ou não é revisitada.

O objeto deste estudo, os manuscritos de "The Burglar of Babylon" escritos pela poeta norte-americana Elizabeth Bishop (1911-1979), aborda o tema da desigualdade social, aspecto da realidade retratado no poema por meio da configuração espacial das favelas cariocas; da situação social de sujeitos que migram para o sudeste do país com a perspectiva de melhores condições de vida; e do exercício da violência direcionada aos ocupantes desses locais. Nesse sentido, a história individual pode revelar aspectos da história de toda uma coletividade. Diante disso, questionamos quais as contribuições que os estudos em crítica genética podem fornecer para o

\footnotetext{
${ }^{1}$ Graduando em Letras - Língua Inglesa e Respectivas Literaturas (UNEB). Bolsista de Iniciação Científica (UNEB/PICIN). Membro do grupo de pesquisa Tradução, Processo de Criação e Mídias Sonoras (PRO.SOM) - UFBA.

${ }^{2}$ Professora Adjunta da Universidade do Estado da Bahia. Doutorado em Literatura e Cultura. Mestrado em Estudo de Linguagens. Graduação em Língua Estrangeira - Inglês. Contato: esbarbosa@uneb.br.

${ }^{3}$ FERRER, D. A crítica genética do século XXI será transdisciplinar, transartística e transemiótica ou não existirá. In: Willemart, P. (Org.) Fronteiras da criação: VI Encontro Internacional de Pesquisadores do Manuscrito. São Paulo: Annablume, 2000, p. 49.
} 
campo da sociocrítica? E de que modo os rascunhos de trabalho de um escritor da literatura podem contribuir para que, a partir das experiências de um indivíduo, se possa denunciar a desigualdade social e o preconceito sofridos por toda uma comunidade?

No que se refere ao dossiê de pesquisa, é composto por 25 fólios datilografados, com rasuras à mão. Os documentos, provenientes da Vassar College, Special Collections, foram consultados em formato fac-símile em um acervo que se encontra no Departamento de Letras Germânicas na Universidade Federal da Bahia, sob os cuidados da professora Dra. Silvia Maria Guerra Anastácio. O dossiê relativo ao poema estudado passou por revisão de sua organização e transcrição. Para cada manuscrito, optamos pelo uso da sigla MS, à qual foi adicionada a numeração 1 a 7 para identificação das 24 peças do prototexto. A transcrição realizada foi a semidiplomática, aquela que respeita, tanto quanto possível, a topografia da página e faz uso de códigos operacionais com a finalidade de representar, já na transcrição, os movimentos realizados pela escritora. Os códigos são provenientes das teses de Anastácio ${ }^{4}$ e Barbosa ${ }^{5}$, já que ambas se debruçam sobre o estudo dos manuscritos da autora em questão:

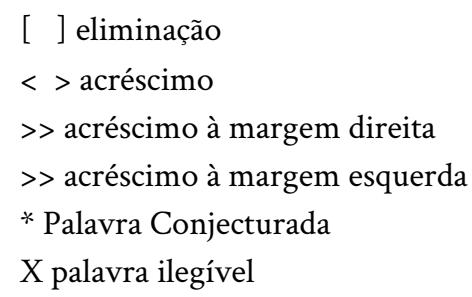

\section{Do real as imaginário de uma poeta}

A temática privilegiada na maior parte dos textos de Elizabeth Bishop é a espacial. As paisagens captadas em sua escrita são transmutadas em signos verbais que remetem a uma figuração de sentidos que tocam a sensibilidade humana. Portanto, a visualidade e a descrição a partir do espaço tornam-se a marca de sua poética ${ }^{6}$.

É necessário pontuar que são poucos os textos de Bishop voltados para a temática social, possivelmente um reflexo de sua postura de evitar posicionar-se politicamente. No Brasil, a escritora frequentava espaços privilegiados, onde conviva com autoridades políticas, escritores e pessoas da alta sociedade brasileira (especialmente de inclinação mais à direita) por intermédio de sua companheira, Maria Carlota Costallat de Macedo Soares, mais conhecida como Lota.

No início da década de 1960, Bishop e Lota, que costumavam permanecer muito tempo em Petrópolis, passaram a residir predominantemente no Rio de Janeiro em apartamento situado no Leme (de onde se podia avistar alguns morros e favelas cariocas). Tal mudança ocorreu em decorrência da candidatura do amigo Carlos Lacerda, eleito governador do Estado de Guanabara, por quem Lota foi convidada a assumir a responsabilidade pela construção do Parque do Aterro do Flamengo em sua gestão, entre 1960 e 1965. Durante esse período, a situação político-econômica brasileira encontrava-se em estado delicado, pois o Rio de Janeiro, não mais capital

4 ANASTÁCIO, S. M. G. O Jogo das Imagens no Universo da Criação de
Elizabeth Bishop. São Paulo: Annablume, 1999, p. 31.

5 BARbosA, Elisabete da Silva. A poética dos espaços na obra de Elizabeth Bishop: uma edição genética dos poemas The Armadillo e North Haven. 2016. Tese (Doutorado em Literatura e Cultura) - Instituto de Letras da Universidade Federal da Bahia, Pós-Graduação em Literatura e Cultura, Salvador, Bahia, 2016, p. 56.

6 SANTIAGo, S. O estatuto do poema descritivo de Elizabeth Bishop. Disponível em: https://revista.abralic.org.br/index.php/revista/article/view/65/66. Acesso em 23 fev. 2020. 
do país, se reestruturava com um projeto de modernização urbana que objetivava redirecionar as populações carentes para outras localidades afastadas dos centros da cidade. As novas moradias, afastadas dos centros onde muitos trabalhavam, não eram satisfatórias para a população, o que intensificou o povoamento em morros e encostas cariocas.

Bishop, em seu livro de viagem intitulado Brazil, explica que a maioria das favelas eram espaços "[...] habitados por migrantes do Nordeste do Brasil. Estima-se que um milhão dos quatro milhões de habitantes do

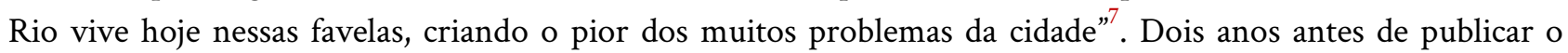
livro, Bishop estava escrevendo "The Burglar of Babylon", texto que retrata, de certa forma, a agitação e os conflitos sociais da época. Trata-se de um processo de criação que recupera elementos da situação política, histórica e social e da configuração espacial das favelas cariocas.

\section{Uma abordagem sociogenética do poema "The Burglar of Babylon"}

O estudo do rastro sócio-histórico do manuscrito proposto por Henri Mitterand ${ }^{8}$ visa a dar lugar ao que denomina genética cultural que, segundo Biasi ${ }^{9}$, é "complementar da história cultural, como a genética literária [...] é para a história literária”. A história cultural, interessada no estudo de aspectos que, por muito tempo, foram desprezados pelo campo histórico, passou a adotar os mais variados objetos, especialmente os relacionados à vida cotidiana. Segundo Barros, "[...] toda a vida cotidiana está inquestionavelmente mergulhada no mundo da cultura através dos modos de vida, das práticas culturais e das representações [...]. A própria linguagem, e as práticas discursivas que constituem a substância da vida social, embasam a noção mais ampla de Cultura”"10.

"The Burglar of Babylon", ao abordar a realidade vivenciada em espaços das favelas cariocas e brasileiras, focaliza a perseguição ao marginal apelidado Micuçú. De origem pernambucana, tornou-se famoso por ter seus crimes, por vezes, noticiados em manchetes de jornais. Por ocasião de sua morte, o jornal Luta Democrática, na edição de 21 de janeiro de 1964, estampou a notícia na primeira página, não sem informar, na chamada da matéria, que Micuçú era considerado o "inimigo público número 1"11.

Para a construção do poema, Bishop consulta noticiários da época, o que revela em entrevista a Ashley Brown: “[...] sentei e escrevi praticamente de uma vez só, com alguns acréscimos e mudanças. A maior parte foi escrita em um dia. Naturalmente se apresentou como uma balada. É uma história verdadeira, tirada de notícias de jornal. Fiz duas pequenas alterações nos fatos" ${ }^{\text {"12 }}$.

Ao resgatar fragmentos do real, o texto toca aspectos sociais importantes. Segundo depoimento da escritora, o poema foi construído a partir de textos jornalísticos. Diante disso, seguimos a sugestão de Mitterand de dar início a um estudo que procure "entender algumas das relações gerativas que unem, em uma sincronia imediatamente anterior ao nascimento da obra, a série dos fatos históricos, a série dos discursos, e a produção do texto" ${ }^{13}$.

${ }^{7}$ BISHOP, E. \& The Editors of LIFE. Brazil. New York: Time Incorporated, 1967, p. 56.

${ }^{8}$ MitTerAnd, H. Crítica genética e história cultural: Zola e os dossiês de Rougon-Macquart. In: ANASTÁCIO, Sílvia et al. Processos de criação interartes. Cinema, teatro e edições eletrônicas. São Paulo: Editora Horizonte, 2014, p. 17-32.

${ }^{9}$ BiAsI, P. M. A genética dos Textos. Trad. Marie-Hélène Paret Passos. Porto Alegre: EDIPUCRS, 2010, p. 135.

10 BARros, J. História cultural e história das ideias: diálogos historiográficos. Disponível em: https://journals.openedition.org/cultura/3353. Acesso em: 25 fev. 2020, s.p.

${ }^{11}$ CavalCanti, T. (Ed.). Com a morte de Micuçu, inimigo público número 1, Cabeleira assume o comando do crime. Luta Democrática, p. 1-2, 1964.

${ }^{12}$ BishOP, E. Uma entrevista com Elizabeth Bishop. Washington, Shenandoah, n. 17, 1966. Entrevista a Ashley Brown. Trad. Carolina Barcellos. In: MONTEIRO, G. (Org.). Conversas Com Elizabeth Bishop. São Paulo: Autêntica, 2013 , p. 35.

${ }^{13}$ Mitterand apud Biasi. Op. cit. 
Os elementos extraliterários, desse modo, ganham destaque na medida em que contribuem para que se possa remontar a história de uma vida, no caso específico deste estudo, a vida de Milton Santos de Oliveira, o jovem apelidado Micuçú. Os manuscritos resultantes da escritura desse poema possibilitam observar como fatos são transfigurados para o espaço ficcional. Ao imortalizar o criminoso, Bishop se inspira no formato da literatura de cordel, gênero que muito apreciava.

A balada é iniciada com a poetização do fenômeno brasileiro de migração em massa ocorrido na década de 1960, devido à seca que assolava a Região Nordeste.

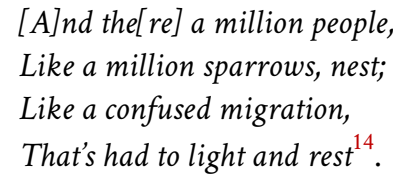

Observamos que o poema, desde seu nascimento, apresenta metáforas bem elaboradas, a exemplo da comparação dos migrantes a andorinhas (sparrows). Ao usar a mesma bacia semântica, as casas desses migrantes são comparadas aos frágeis ninhos construídos por esses pássaros. O poema é iniciado com a descrição do cenário onde ocorre perseguição da polícia a Micuçú. Tal espaço ficcional mimetiza o espaço real da favela localizada no Morro da Babilônia, com a ênfase para a fragilidade social das pessoas que ali habitavam, representada pela falta de material adequado para a construção de suas moradias: "They make their nests, or houses, / Out of nothing at all, or air" ${ }^{\prime 15}$. Ainda no MS1, Bishop relaciona o apelido do criminoso a um Marmoset, cujo sentido em português refere-se a um "mico com um rabo longo e espesso que vive na América Central e América do Sul” ${ }^{\text {16 }}$. A tentativa de encontrar um significado para o apelido da personagem reaparece no MS3, em que há um questionamento se a palavra significaria "animal selvagem".

( ${ }^{*}$ Micoçú Mè-cō-soo) a nickname [meaning] "Dirty Marmoset"(MS1, fólio 1, Box. 58.3)

"Micucu means "wild animal"? favela ${ }^{17}$.

$\mathrm{Na}$ versão publicada, Bishop estabelece um significado diferente dos propostos nos manuscritos: “*Micuçú $(M \bar{e}-c \bar{o}-s o o)$ is the folk name of a deadly snake, in the north" ${ }^{18}$. Mesmo abordando a temática cruel da desigualdade social e de suas consequências, o poema, talvez por sua sonoridade agradável, foi ilustrado por Ann Grifalconi para o público infantil com o título The Ballad of the Burglar of Babylon. Na introdução para esse volume, Bishop explica que

[...] at the time, people said that the name Micuçu was short for Mico Sujo, or 'Dirty Marmoset', but finally it was decided that this was wrong and that it is the coloquial name for a deadly snake, in the north of Brazil. A Young man trying to be a real gangster, like in the films, would certainly prefer to be called by the name of a deadly snake ${ }^{19}$.

\footnotetext{
${ }^{14}$ Bishop, E. Published Poetry. The Burglar of Babylon. Elizabeth Bishop Collection, Vassar College, Poughkeepsie, New York, [1964], Box 58.6, MS1, folio 1.

${ }^{15}$ Ibidem., MS1, fólio 1.

${ }^{16}$ WeHMEIER, S. (Ed.). Oxford Advanced Learner's Dictionary of Current English. Oxford: Oxford University Press, $2000, \mathrm{p}$. 818.

${ }^{17}$ Op. cit., MS3, folio 1.

${ }^{18}$ Bishop, E. Poemas escolhidos de Elizabeth Bishop. Trad. Paulo Henriques Brito. São Paulo: Cia das Letras, 2011, p. 264.

${ }^{19}$ EsTeSs, S.; SCHWARTZ, L. Elizabeth Bishop and her art. Michigan: The University of Michigan Press, 2002, p. 305.
} 
O apelido da personagem tem alteração das vogais "o" e "u" no primeiro manuscrito, porém, a partir da versão MS2, Bishop fixa a escrita do nome do marginal em Micuçú, cuja ortografia frequentemente aparecia estampada em jornais da época.

Após sua morte em 19 de janeiro de 1964, a imagem de Micuçú e a do Morro da Babilônia, local onde foi capturado, foram bastante evidenciadas. No que diz respeito a essa visibilidade midiática, vale ressaltar que, na década de 1960, o índice de criminalidade era alto e o sensacionalismo, já presente nas décadas anteriores, rendeu aos criminosos títulos de anti-heróis. Segundo Azevedo, nas décadas de 1950 e 1960, “[...] a mídia 'construiu' a carreira de bandidos de menor periculosidade - mas igualmente repelidos pela sociedade - tais como 'Mineirinho', 'Cara de Cavalo', 'Tião Medonho', o próprio 'Micuçú', além de outros menos afamados”20.

Quando Bishop foi perguntada, em entrevista por Ashley Brown, se realmente acompanhou a caçada à Micuçú, ela respondeu: "Não, mas vi os soldados. Dava pra vê-los com binóculos do terraço onde eu estava":

I was one of those who watched the pursuit through binoculars, although really we could see very little of it: just a few of the soldiers silhouetted against the skyline of the hill of Babylon. The rest of the story is taken, often word for word, from the daily papers, filled out by what I know of the place and the people $e^{21}$.

$\mathrm{O}$ uso de jornais da época pela escritora como fonte indicia um processo de criação que estabelece intertextualidade com material de gênero informativo. Desse modo, a proposta de um estudo sociogenético mostra-se relevante, na medida em que se debruça sobre os documentos de trabalho da escritora como rastro para a reconstrução de uma história de vida. Bishop, tendo acompanhado a perseguição a Micuçú, nos permite reiterar o que percebemos em outros estudos acerca de seu processo criativo, a saber, a tendência de criar a partir do que experimenta ou observa.

\section{o processo de criação do cenário percorrido por Micuçú}

O espaço e os procedimentos de multiterritorialização são vetores do processo criativo para a construção do cenário em que o poema é ambientado. A categoria espacial é aqui acionada para que melhor possamos entender a condição social das personagens que entram em cena no poema "The Burglar of Babylon". Os espaços retratados podem reunir significações que dizem respeito à relação sujeito e ocupação territorial e podem ser interpretadas a partir do conceito de multiterritorialidade proposto por Haesbaert ${ }^{22}$.

O conceito de território pressupõe a relação de dominação do sujeito com um espaço determinado. Haesbaert, então, ao buscar bases filosóficas para a ampliação do conceito, propõe que o indivíduo pode manter elos multiterritoriais não apenas com um único território. Para fundamentar tal construção conceitual e teórica, encontra em Deleuze e Guatarri caminhos para pensar o componente territorial de forma mais ampla, perpassando as dimensões física, mental, social, política, simbólica, afetiva e psicológica, por exemplo. Para Haesbaert $^{23}$, a territorialização e a desterritorialização têm dimensões múltiplas, o que abre caminho para pensarmos os movimentos de territorialização, desterritorialização e reterritorialização como sucessivos, dando lugar ao conceito de multiterritorialidade.

\footnotetext{
${ }^{20}$ AzEVEDO, J. Os bandidos da Babilônia. Belas Infiéis, Brasília, v. 1, n. 1, p. 55-68, 2012.

${ }^{21}$ Op. cit, p. 305.

${ }^{22}$ HAESBAERT, R. O mito da desterritorialização. Do fim dos territórios à multiterritorialidade. Rio de Janeiro: Bertrand Brasil, 2007.

${ }^{23}$ Ibidem.
} 
Em suas palavras, um indivíduo não permanece desterritorializado por muito tempo; se privado de alguma das possíveis instâncias da territorialidade, logo encontra meios de reterritorializar-se na mesma ou em outra instância. A complexidade de tal relação instiga a refletir sobre os diversos modos que o sujeito dispõe para apropriar-se de territórios diversos.

Bishop, no texto, incorpora marcos referenciais, a exemplo das favelas mencionadas no poema. A cena se desenvolve no Morro da Babilônia, espaço no qual muitos dos migrantes caracterizados nas cinco primeiras estrofes do poema almejam uma reterritorialização física, mesmo que em habitações precárias. No entanto, essa população frequentemente vivencia processos de desterritorialização, pois são, em sua maioria, excluídos das esferas econômica e política, para mencionar as duas mais atuantes nas possibilidades de escolha de cada indivíduo. Os modos de reterritorialização, embora mais restritos, são frequentemente reinventados por pessoas que, no geral, ficam à margem das políticas públicas. Por isso, podemos afirmar que o sujeito, ser sociocultural, está em contínuo trânsito entre diversas territorialidades com vistas a atender as próprias necessidades e a buscar melhor qualidade de vida; apropria-se, pois, de múltiplos territórios.

Com este artigo, intentamos dialogar com algumas questões levantadas por Biasi ${ }^{24}$ : "Em quais condições e limites a crítica genética pode contribuir para a elaboração de uma história dos processos culturais? Qual sentido dar à ambição de apreender geneticamente o rastro sociohistórico nos manuscritos, de fazer a hipótese de uma 'sociogênese?"'

A partir de tais questões e norteados pelos conceitos já apresentados, consultamos jornais do ano de 1964 nos quais o rastro histórico da saga de Micuçú é registrado. Essa personagem, como tantos outros jovens da periferia, acabou encontrando no mundo do crime um caminho para estabelecer-se socialmente. O Jornal Última Hora de 20 de janeiro de 1964 foi uma de nossas principais fontes e supomos ter sido lido por Bishop, pois apresenta algumas das especificidades narradas em "The Burglar of Babylon". Passamos então a realizar um estudo comparativo entre os fragmentos desse jornal e nosso prototexto.

ALCAGUETADO - A 'blitz' que culminou na morte de 'Micuçu' começou por volta das 20.30 horas de sábado, quando o bandido apareceu no Morro da Babilônia procurando o barraco de D. Nadir de Almeida Resende. Sua presença na tendinha da subida do morro despertou suspeitas aos que lhe deram a informação. Todos sabiam que D. Nadir era tia de 'Micuçu', e que ganhou cartaz no morro quando da prisão do assassino ${ }^{25}$.

Algumas informações contidas no fragmento acima são recuperadas por Bishop. Por exemplo, a tendinha mencionada no jornal, de propriedade da tia de Micuçú, aparece na primeira versão do poema como um estabelecimento onde se vende bebida alcoólica (drink-shop):

They said he'd visit his Auntie
Who'd raised him like a son.
She has a little drink-shop
On the hill of Babylon ${ }^{26}$.

Observamos que a primeira versão produzida por Bishop a partir do jornal é similar à versão publicada, em que há ajuste somente no primeiro verso, formato estabelecido a partir do MS5, com a troca da locução verbal he'd visit (ele visitaria) por he'll go (ele irá): "They said 'he'll go to his auntie" (MS5, fólio 1). Além disso, o trecho jornalístico informa que a perseguição a Micuçú foi iniciada às 20:30. Bishop seleciona então tal fragmento da

\footnotetext{
${ }^{24}$ Op. Cit. p. $134-135$.

${ }^{25}$ ÚLTIMA Hora. Rio de Janeiro, p. 12, 20.01.1964.

${ }^{26}$ Op. cit. MS2, fólio 1.
} 
realidade para a composição da balada, com o verso "All night, under the stars" (MS1, fólio 2), como observamos no trecho a seguir:

$\begin{array}{ll}\text { and rich people down below } & \\ \text { watched through binoculars } & \text { >till it was too dark to see>> } \\ \text { peerked up at the fair green hill } & \text { > all night under the stars }-> \\ \text { All night under the stars }{ }^{27} . & \end{array}$

No fragmento apresentado, encontramos duas versões. A primeira, datilografada, organiza-se na margem esquerda da página. Nela, há a informação de que o evento se passou à noite. No entanto, esse mesmo manuscrito apresenta outra versão, feita com um acréscimo à mão, posicionada à direita da página, com a informação de que o evento teria iniciado ainda com a luz do dia e teria se estendido pela noite, "till it was" too dark to see". Essa ideia é preservada, mas modificada em sua forma para trazer mais ritmo, considerando-se o conjunto do poema. Desdobra-se, então, para o formato final do verso, "As long as the daylight lasted" ${ }^{\text {"2 }}$, sem registro em manuscrito.

O fragmento de jornal ainda apresenta a informação de que Micuçú seria um assassino. No MS1, Bishop insere uma quantificação dos assassinatos (sete) e dos eventos de fuga da penitenciária (duas).

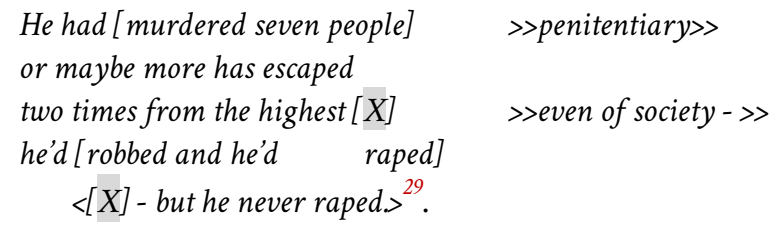

Embora Bishop utilize os jornais da época como fonte de pesquisa para a construção do poema, observamos que o processo criativo, mesmo quando parte de uma suposta realidade, opera uma transfiguração no sentido de se alcançar objetivos estéticos. Além disso, podemos considerar que a produção artística e as transfigurações que propõe não são neutras e, portanto, acabam evidenciando os alinhamentos políticos da escritora.

No MS4, as fugas de Micuçú são fixadas em três, informação não apresentada nos jornais consultados. Nessa versão, Bishop acrescenta que a personagem é inimig a da sociedade, trecho inspirado no jornal $A$ Luta Democrática ${ }^{30}$.

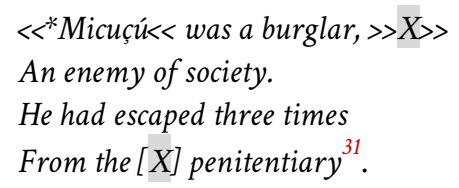

O excerto seguinte, do jornal Última Hora, traz informações a respeito da reação da tia de Micuçú que o vê em fuga e não pode abrigá-lo, sob o risco de tronar-se cúmplice do marginal.

RECUSADO - D. Nadir levou o maior susto com a visita inesperada do sobrinho bandido, e uma vez recuperada, suplicou-lhe que fosse embora, pois ela, o marido e o filho eram gente

\footnotetext{
${ }^{27}$ Ibidem., MS1, fólio 2.

${ }^{28}$ Op. cit., p. 250.

${ }^{29}$ Op. cit., MS1, fólio 2.

${ }^{30}$ Op. cit.

${ }^{31}$ Op. cit., MS4, fólio 1.
} 
honesta e trabalhadora: 'Não queremos nos envolver em assunto de polícia!'. Desolado - ela própria conta - o fugitivo pulou a cerca dos fundos embrenhando-se na favela. Antes, porém, D. Nadir serviu-lhe o jantar, durante o qual deu-lhe alguns conselhos. Micuçú, quando partiu, mancava da perna direita ${ }^{32}$.

A ida à casa da tia à procura de um esconderijo configura uma tentativa de se reterritorializar. No poema, tais informações aparecem dispersas em estrofes distintas. Na primeira, há um deslocamento em direção à casa da tia, caracterizada mais como um local de passagem do que como um esconderijo. Desse modo, o possível efeito poético causado no leitor é que Micuçú intenta despedir-se de uma pessoa querida.

No texto jornalístico, há uma representação de um jantar servido pela tia, como quem oferece um último alimento a quem se sabe estar com os dias contados. Tal fragmento foi transmudado no poema para um momento em que Micuçú e a tia, juntos, bebem cerveja.

Desse modo, a personagem Micuçú, em fuga, não se demora nesse espaço. A rápida visita, uma despedida, traz a conotação de que, embora Micuçú tenha adentrado o mundo do crime, é um ser humano com sentimentos e fragilidades.

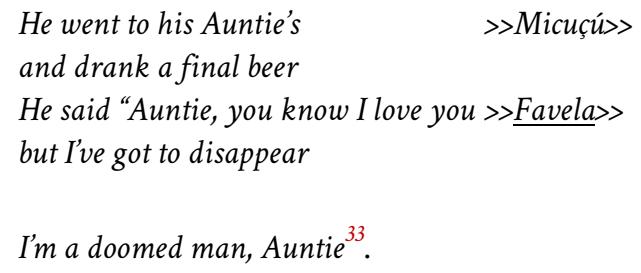

O manuscrito literário torna-se o locus privilegiado para melhor se observar as diversas camadas textuais produzidas na escrita, as quais, de certa forma, são presentificadas no texto final e é responsável por sua plurissignificação. Embora haja um reforço imagético que caracteriza Micuçú como um sujeito perverso e perigoso, em alguns momentos a escritora recorre a uma dimensão afetiva, o que imbui a personagem de um pouco mais de complexidade.

Micuçú e a tia, por certo, já sabiam qual seria seu triste fim. Há, no poema e no texto jornalístico, referência ao fato de a tia afirmar a honestidade de sua família, o que Bishop enfatiza em duas estrofes distintas. Trata-se de um valor com o qual a maioria das pessoas habitantes das favelas procura se identificar. No MS1, a figura da tia aparece ao lado do adjetivo respeitada (respected).

\section{His Auntie said he was bad his sister has a good job the aunt is very respected - why did he have to rob? ? $^{34}$}

Bishop traz para o poema outra personagem com laços de parentesco, a irmã de Micuçú, não mencionada nos jornais consultados. O fato de o texto poético informar que ela tem um bom emprego parece estar relacionado com a perspectiva de se criar um contexto familiar de honestidade, o que gera um jogo dialético entre as qualidades precárias de moradia, segurança e aderência do poder público nesses espaços com a sustentação de uma territorialidade que, embora precária, se faz múltipla, por apoiar-se em dimensões de ordem mais simbólica.

\footnotetext{
${ }^{32}$ Op. cit., p. 12, 20.01.64.

${ }^{33}$ Op. cit., MS1, folio 2.

${ }^{34}$ Ibidem., MS1, folio 2.
} 
A qualidade respeitável atribuída à família é novamente reforçada na preparação de outra estrofe, registrada pela primeira vez no MS2. Foi escrita à mão, com indicação da posição que deve ocupar na página. Somente no MS4 é que as duas estrofes aparecem, uma seguida da outra, como acontece com a versão final do poema.

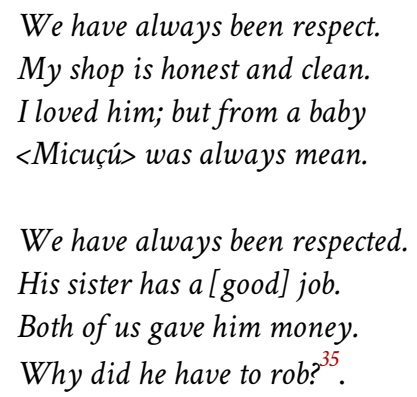

Destacamos algumas recorrências ao longo das versões do poema, a exemplo dos versos "He had [murdered seven people]"36, "His Auntie said he was bad"37 "An enemy of society"," "<Micuçú> was always mean", o que evidencia, em uma primeira camada de leitura, uma caracterização da personagem a partir de uma inclinação maior para um pensamento binário, ainda vigente em muitas narrativas, o qual estabelece sistemas de valoração construídos a partir de oposições. O texto, ao dar maior evidência a uma suposta maldade inerente à personagem Micuçú, está mais alinhado aos pressupostos de um determinismo social, que não problematiza em profundidade os agenciamentos diversos que perpassam os sujeitos.

No entanto, ao aplicar uma leitura que busca outras esferas de significação expressas por meio da mesma linguagem que intentou construir uma imagem negativa de sujeito, outros elementos indiciam que, mesmo "The Burglar of Babylon" sendo um texto ficcional e seu personagem principal esteja envolto por uma carga de significação pejorativa, ele torna-se um ser complexo, pois construído na e pela linguagem.

No momento em que Micuçú se sente acuado, vivenciando um processo de desterritorialização de ordem física, intenta reterritorializar-se na casa da tia, pois, além do espaço material, possivelmente estava em busca de uma territorialização afetiva e psicológica, embora soubessem, ele e a tia, que esse seria um dos primeiros locais a serem percorridos pela polícia. A tia, não aceitando a permanência do sobrinho por não querer envolver-se com aquela situação, acolhe momentaneamente o criminoso, dando-lhe um prato de comida. No poema, o cuidado da tia é evidenciado com o emprego de verbo de conotação mais afetiva, loved.

Em outro trecho do jornal, a polícia aperta o cerco, aproximando-se do esconderijo de Micuçú, momento em que ele experimenta novamente a sensação de estar desterritorializado:

CÊRCO - Apesar do incidente, as buscas prosseguiram, incluindo os Morros Chapéu Mangueira, Cera de Cão e Santa Teresinha. O cerco, cada vez mais apertado, não deixava 'chance' para a fuga. Seu 'tête à tête' com a polícia não foi, até agora, esclarecido ${ }^{40}$.

Na matéria, não se especifica o lugar onde Micuçú fora encontrado. Do mesmo modo, Bishop deixa indefinido o local do esconderijo, indicando, apenas, possibilidades.

\footnotetext{
${ }^{35}$ Ibidem., MS4, folio 4.

${ }^{36}$ Op. cit., MS1, fólio 2.

${ }^{37}$ Ibidem.

${ }^{38}$ Op. cit., MS4, fólio 1.

${ }^{39}$ Op. cit., MS4, folio 4.

${ }^{40}$ Op. cit., p. 12.
} 


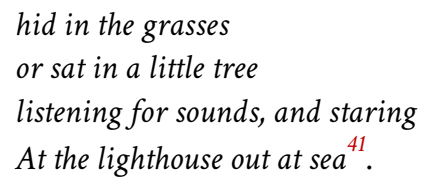

O que observamos a partir dessa análise é que a exclusão socioespacial e a desterritorialização caminham juntas, o que é indiciado com a trajetória de Micuçú, retratada de forma poética por Bishop. A escritora habilmente busca as raízes nas quais o processo de exclusão dos moradores de favelas começa. Acaba, pois, explicitando as consequências drásticas de tal exclusão, o que é ilustrado com a narrativa sobre Micuçú.

A respeito da morte da personagem, o jornal Última Hora narra duas versões. Na primeira, apresentada pela Polícia Militar, o marginal teria sido capturado e transportado dentro de um jipe. Muito machucado, não resiste e acaba falecendo.

MISTÉRIO - O cadáver do marginal chegou ao $12^{\circ} \mathrm{DP}$ cerca de uma hora depois de o rádio da Polícia haver anunciado que 'Micuçu' havia sido prêso e embarcado num jipe da PM. A versão oficial é a seguinte: o Segundo Tenente da PM Carlos Antonio de Albuquerque, num gesto de coragem, resolveu colaborar nas buscas e, afastando-se cerca de 1000 metros do seu posto (Comando Militar do Morro do Leme), acompanhado de soldados, embrenhou-se na mata. Momentos depois, deparou com um vulto, aparentemente ferido. Quis sacar sua arma, mas foi contido pelos soldados, que prenderam 'Micuçu'. O bandido morreu no jipe, a caminho do hospital $^{42}$.

No entanto, há uma segunda versão, fornecida pela Polícia Civil:

SUSPEITAS [...] uma outra hipótese foi aventada pela Polícia Civil, que se encarregou de espalhá-la como sendo 'a verdade'. Conta esta segunda versão que 'Micuçu' teria mesmo sido prêso ainda com vida por um grupo de PM [...] Depois de seguidamente espancado, o bandido foi embarcado no jipe que o levaria ao Distrito. No interior da viatura, teria sido baleado e massacrado até a morte.

FERIMENTOS - Os ferimentos constatados no cadáver de Micuçú vêm confirmar a segunda versão. Seu corpo apresentava fortes marcas de sevícia: alguns ferimentos a bala e uma perfuração na altura do ouvido direito. O corpo do bandido foi removido para o Instituto Médico Legal $[\ldots]^{43}$.

Bishop opta por trazer para o poema alguns elementos contidos na versão fornecida pela Polícia Civil, a exemplo de um tiro desferido contra o ouvido de Micuçu, o que poderia indiciar a truculência com que a polícia brasileira atua. No entanto, na mesma estrofe em que essa informação é apresentada, Bishop recorre, mais uma vez, a um pensamento que se constrói de forma binária, de modo a eliminar os traços da violência policial ao caracterizá-los com o sentimento de medo. O temor dos policiais ficcionalizado no poema atua no sentido de enfatizar a caracterização de Micuçú como um ser perverso e violento.

The soldiers were afraid

they never got very near

he made a dash for a crevice

\footnotetext{
${ }^{41}$ MS2, folio 2

${ }^{42}$ Op. cit., p. 12.

${ }^{43}$ Ibidem.
} 


$$
\text { and got in, behind the ear }{ }^{44} \text {. }
$$

Sem o poder de representar-se, Micuçú foi amplamente representado pela mídia num período em que os marginais faziam fama no Brasil. Decerto, Bishop foi influenciada por diversas narrativas veiculadas à época, mas, igualmente, propôs uma versão própria, recorrendo aos princípios da estética literária. Para além dos textos midiáticos no qual se inspirou, acreditamos que o olhar da estrangeira, ao deparar-se com as questões sociais do Brasil, acabou reproduzindo alguns dos estereótipos característicos de uma sociedade altamente estratificada.

A estrofe acima registra o fim de Micuçú. Porém, não o fim do poema e de toda a problemática com a qual ele se propõe a dialogar. A estrutura textual é circular, com as duas últimas estrofes mimetizando aquelas posicionadas no início do texto. Tal registro, não encontrado nos manuscritos aos quais tivemos acesso, somente se presentifica na versão publicada:

$$
\begin{aligned}
& \text { On the fair green hills of Rio } \\
& \text { There grows a fearful stain: } \\
& \text { The poor who come to Rio } \\
& \text { And can't go home again }{ }^{45} \text {. }
\end{aligned}
$$

O aumento do quantitativo de habitantes das favelas e a falta de políticas públicas voltadas à população são retratados com a metáfora de uma mancha ou mácula crescente (There grows a fearful stain). As cinco primeiras estrofes apontam para tal situação. A partir da sexta, a saga de Micuçú começa a ser narrada. Trata-se de um poema longo, organizado em 47 estrofes. A última, também idêntica à quinta, indicia que o problema abordado não é isolado, mas fruto da desigualdade social e da pobreza que massacra e, por vezes, desvirtua o caráter.

\section{There's the hill of Kerosene, And the hill of the Skeleton, The hill of Astonishment, And the hill of Babylon ${ }^{46}$.}

Trata-se de uma textualidade que menciona, além do Morro da Babilônia, três outros espaços cujas denominações remetem ao perigo ou ao efeito causado em quem com ele se depara: Morro do Querosene, do Esqueleto, do Pasmado e da Babilônia. Lugares de onde, vez por outra, surge um Micuçú.

No que diz respeito à representação desse sujeito posto à margem da sociedade, pode ser compreendido como um ser predominantemente desterritorializado, pois, por estar foragido - e, antes de entrar para a criminalidade, vivenciar a privação material característica de ambientes empobrecidos da cidade -, precisou deslocar-se à procura de abrigos com a finalidade de evitar ser preso novamente. Nos manuscritos, é possível compreender que a personagem vai sendo formatada a partir dos múltiplos territórios em que transita em busca de uma reterritorialização.

\section{Referências}

AnaStaCiO, S. M. O jogo das imagens da criação de Elizabeth Bishop. São Paulo: Annablume, 1999.

\footnotetext{
${ }^{44}$ Op. cit., MS1, folder 2.

${ }^{45}$ Op. cit., p. 276.

${ }^{46}$ Ibidem.
} 
Azevedo, J. Os bandidos da Babilônia. Belas Infiéis, v. 1, n. 1, p. 55-68, 2012. BARRos, J. História cultural e história das ideias: diálogos historiográficos. Disponível em: https://journals.openedition.org/cultura/3353. Acesso em: 25 fev. 2020.

BIASI, P. M. A genética dos textos. Trad. Marie-Hélène Paret Passos. Porto Alegre: EDIPUCRS, 2010, p. 39-65. BISHOP, E. \& The Editors of LIFE. Brazil. New York: Time Incorporated, 1967.

BISHOP, E. Poemas escolhidos de Elizabeth Bishop. Trad. Paulo Henriques Brito. São Paulo: Cia das Letras, 2011.

BISHOP, E. Published Poetry. The Burglar of Babylon. Elizabeth Bishop Collection, Vassar College, Poughkeepsie, New York, [1964], folder 58.6.

BISHOP, E. Uma entrevista com Elizabeth Bishop. Washington, Shenandoah, n. 17, 1966. Entrevista a Ashley Brown. Trad. Carolina Barcellos. In: MonTEIRO, George (Org.). Conversas com Elizabeth Bishop. São Paulo: Autêntica, 2013 [1966], p. $41-53$.

Cavalcanti, T. (Ed.). Com a morte de Micuçu, inimigo público número 1, Cabeleira assume o comando do crime. Luta Democrática, p. 1-2, 1964.

ESTESS, S.; SCHWARTZ, L. Elizabeth Bishop and her art. Michigan: The University of Michigan Press, 2002.

FERRER, D. A crítica genética do século XXI será transdisciplinar, transartística e transemiótica ou não existirá. In: WILlEMART, P. (Org.) Fronteiras da criação: VI Encontro Internacional de Pesquisadores do Manuscrito. São Paulo: Annablume, 2000.

HAESBAERT, R. O mito da desterritorialização. Do fim dos territórios à multiterritorialidade. Rio de Janeiro: Bertrand Brasil, 2007.

MAGAlHÃES, A. Remoções de favelas no Rio de Janeiro: entre formas de controle e resistências. Curitiba: Appris, 2019.

MitTerand, H. Crítica genética e história cultural: Zola e os dossiês de Os Rougon-Macquart. In: ANASTÁCIO, S. M. et al. Processo de criação interartes: cinema, teatro e edições eletrônicas. Trad. Sirlene Góes, Sílvia Anastácio e Richard Hartley. São Paulo: Editora Horizonte, 2014. p. 17-32.

Monteiro, G. (Org.). Conversas com Elizabeth Bishop. Trad. Rogério Bettoni. Belo Horizonte: Autêntica, 2013.

SANTIAGO, S. O estatuto do poema descritivo de Elizabeth Bishop. Disponível em: https://revista.abralic.org.br/index.php/revista/article/view/65/66. Acesso em 23 fev. 2020.

ÚlTIMA Hora. Rio de Janeiro, p. 12, 20.01.1964.

WeHMEIER, S. (Ed.). Oxford Advanced Learner's Dictionary of Current English. Oxford: Oxford University Press, 2000 . 